\title{
The role of care-giver and mental health for older adults with disabilities: a mixed-method study
}

\author{
Shuoao Huang ${ }^{1}$, Qi Zhao ${ }^{1}$, Xiaoting Liu ${ }^{1,2 *}$ (D) and Yanyan Jin ${ }^{1}$ \\ ${ }^{1}$ School of Public Administration, Zhejiang University, Hangzhou, China and ${ }^{2}$ Center of Social Welfare and \\ Governance, Zhejiang University, Hangzhou, China \\ *Corresponding author. Email: xtliu@zju.edu.cn
}

(Accepted 6 September 2021)

\begin{abstract}
Because of the exacerbation of population ageing, more family members are involved in the informal care-giving for older adults with disabilities to cater to their long-term care needs. As informal care-givers are associated with the mental health of the care recipient, this study, based on the theoretical framework of the Actor-Partner Effect, utilises a mixed method composed of quantitative and qualitative strategies to identify the relationship among gender and type of both care-giver and care recipient, and mental health of the recipient and explain its internal mechanism. In the quantitative research, ordinary least squares (OLS) regression results based on the basis of the Chinese Longitudinal Healthy Longevity Survey (CLHLS) data corroborate the existence of actor and partner effects within the care-giving dyad. The qualitative analysis further explains the socially constructed differences in gender role, trust relationship and perception towards filial piety of adult care-givers playing their role in the emergence of the Actor-Partner Effect. Finally, this study proposes a developed Actor-Partner Effect analysis framework, advocating to destigmatise disability and construct social support networks for the older adults with disabilities who receive informal care to promote their mental health based on the reflection of socially constructed gender difference.
\end{abstract}

Keywords: care recipient; care-giver; mental health; Actor-Partner Effect

\section{Introduction}

With life expectancy getting longer, the population is ageing at an unprecedented rate in China. At the end of 2018, the size of the older population aged 60 years and over in China was 249 million, accounting for 17.9 per cent of the total population $(\mathrm{Mu}, 2016)$. However, healthy life expectancy does not show a significant corresponding ascent. There were about 40.63 million elderly people with partial or complete disability in China in 2016, and the number is estimated to soar to 61.68 million by 2030 (The National Working Commission on Aging, 2016). As the number of older adults with disabilities soars, their long-term care needs 
mount at the same time, which indicates that more people are involved in caregiving activities. However, due to the socio-economic and cultural transition and the implementation of the one-child policy, the availability and quality of informal care is declining, which suggests that more disabled elderly people who are cared for within their families have been experiencing unmet long-term care needs (Chen et al., 2018; Luo and Zhan, 2018). While care-givers are strongly associated with the wellbeing of older adults with disabilities, the impact of the care-giver's role on the mental health of the older care recipient has not been the subject of practical research so far.

\section{Mental health of older adults with disabilities}

As the number of older people with disabilities is booming, more individuals are at risk of experiencing mental health issues. According to the World Health Organization (2017), approximately 15 per cent of adults aged 60 and over suffer from a mental disorder worldwide. Since physical health has an impact on mental health, people with disabilities report higher rates of mental health problems, such as anxiety and depression, than those without disabilities (Centers for Disease Control and Prevention, 2019). Impaired mental health would significantly affect the general health of individuals as well. For example, the mortality of older adults increases dramatically with mental health disorders (Rozzini et al., 2002). While the older people with disabilities are more vulnerable to both physical and mental illnesses, they have got relatively inadequate attention compared with their caregivers. Traditionally, the focus of care-giving research has been on the wellbeing of care-givers, studying the negative outcomes of being involved in care-giving (Lyons et al., 2002). Care recipients who are cognitively intact and have sufficient care-givers are often assumed to function satisfactorily, both physically and mentally (Purdy and Arguello, 1992). In fact, the mental health of older care recipients intertwines with care-givers, and increasing numbers of older care recipients are faced with mental health deterioration, due to the interactions with their primary informal care-giver (Allen and Mor, 1997).

Existing studies suggest that informal care-givers, considering their role and interactions with care recipients, are associated with the mental health of the care recipients (Marks and Choi, 2002; Buber and Engelhardt, 2008; Ejem et al., 2018). First of all, support from adult children benefits the mental health of older parents by reducing their depressive symptoms (Buber and Engelhardt, 2008; Byers et al., 2008). In terms of the gender of adult children, Zeng et al. (2016), utilising binary and ordered logistic regressions as well as linear regressions, found that daughters' support helps older adults to maintain better mental health status, compared with that of having the help of sons. Secondly, care-giver burden, apart from kinship and gender, is another factor which influences care receivers' mental health. Care-givers who reported higher levels of objective burden were associated with an increase in care recipients' depressive symptoms (Ejem et al., 2018). Considering spouses, adult children and children-in-law as care-givers, spousal care-givers tend to report a higher care-giving burden. Compared with men, female care-givers showed higher levels of burden while providing care to older adults (Gallicchio et al., 2010). Furthermore, the care-giving relationship 
also plays its part in the mental health of care recipients. Care recipients who enjoy reciprocity and respect afforded by their primary care-givers show lower likeliness of being identified as depressed (Wolff and Agree, 2004). Care-givers' resentment resulting from their care-giving obligations negatively impacts on the quality of informal care and the mental health of care recipients (Williamson et al., 2005). Meanwhile, the care-giving relationship is related to the care-giver's role: older adults in need experience better relationships with their daughters than with their sons, while children-in-law are more likely to have a negative relationship with the recipients of their care (Pinquart and Sorensen, 2011; Zeng et al., 2015). Besides this, disabled older parents' dissatisfaction with the care from their sons and daughters-in-law due to conflict between daughters-in-law and mothers-in-law increases as husbands and wives more equally negotiate elderly care arrangements (Zhang and Wang, 2010; Zeng et al., 2015). What is more, the negative interactions, such as marital conflict, between the husband-and-wife partnerships of care-giving dyads are a significant predictor for depression in the recipients of care (Newsom and Schulz, 1998).

\section{The transition of preferred care-giver and care-giving arrangement in China}

In the Chinese context, families still play a major role in caring for older adults due to the influence of Confucian philosophy, especially for those who are disabled. Therefore, more and more family members are engaged in care-giving because of the growing population ageing (Li and Dai, 2019). Analysis of the 2011 wave of the Chinese Longitudinal Healthy Longevity Survey (CLHLS) showed that nearly 88 per cent of assistance with activities of daily living (ADLs) for older adults came from family members, where spouses, sons, daughters-in-law and daughters were the major providers (Zhuang and Zhang, 2016). While families give priority to care-giving for older people with disabilities, the practical long-term care arrangement is influenced by certain factors.

The gender of older people with disabilities is associated with their long-term care needs and care-giving arrangement. The number and proportion of female older people with disabilities outweighs males, and they are more susceptible to impairment in activities in daily living and more dependent on others for assistance compared with male counterparts. In the case of informal care-giving arrangements, male care recipients receive more informal care from spouses while females tend to be cared for by adult children. In addition, compared to male peers, older women with disabilities account for a higher percentage having a daughter as the major care-giver (Zhuang and Zhang, 2016).

While the preference for a primary informal care-giver in China has been undergoing a significant shift, care-giving arrangements within families may change correspondingly. In terms of patriarchal tradition based on Confucianism, son preference (which indicates that sons are expected to undertake more family responsibilities) has been at the root of elder-care for thousands of years. Parents tend to invest more in male children in exchange for care-giving when they need it in later life, while daughters are deemed to be members of their husbands' extended families after they 'marry out' (Deutsch, 2006; Ebenstein and Leung, 2010). However, it is noteworthy that the informal care-giving pattern is shifting 
in modern China. On the one hand, according to recent research, daughters are providing equivalent or even more support for their parents than is provided by sons (Xie and $\mathrm{Zhu}, 2009 ; \mathrm{Hu}, 2017$ ); and a study contended that there is not much difference for elderly recipients of care between receiving care from sons or daughters (Hu and Chen, 2019). Moreover, the idea of daughters being the preferred care-givers has been corroborated by certain research (Tang et al., 2009). This change can be attributed to the process of modernisation, which promotes the model of the conjugal family and further sets people free from the bounds of the extended family system and patriarchal traditions (Hu and Chen, 2019). In addition, the gender roles for children-in-law have been weakening in terms of care for older adults, due to the social change in spousal socio-economic status (SES) and living arrangements (Hannum, 2005; Yan, 2009). Daughters-in-law, who are traditionally introduced into elderly care as primary care-givers to provide hands-on care for aged parents under the heading of filial piety as part of the responsibilities of their husbands, are less likely to be obliged to undertake most care-giving tasks given their increasing power within families (Chi and Merril, 2011). Thus, there is a preference among older adults to choose their unmarried children to take responsibility for their care in old age (Zheng et al., 2012).

On the other hand, the trend of shrunken family structures brings elderly spouses into the position of primary care-giver because of the proximity effect. Due to the implementation of the one-child policy, and greater economic and geographic mobility, the overall scale of extended family has shrunk dramatically in China, and the nuclear family is gradually taking precedence, which indicates that the availability of traditional 'feed-back' family care based on co-residing living arrangements is declining (Zhan, 2004; Sheng and Settles, 2006). The ensuing increments of the '4-2-1' intergenerational family structure have imposed heavier burdens on more adult children for supporting their parents, while the only child who is their parents' intended care-giver tends to put work before parental care because of the mounting financial burden. Meanwhile, changes in the economy, culture and society in recent years, which weaken filial obligation, reinforce the independence of older adults (Zheng et al., 2012). An existing study demonstrated that spousal care was the most preferred choice in caring for older adults in need in contemporary China, even when an older couple lived with their adult children (Li and Dai, 2019).

This article aims to define the association between the informal care-giving pair's role (in terms of gender and type) and the mental health of the care recipient as well as the influential factors within. While existing literature has investigated the impact of care-givers on the mental health of care recipients, the subjective affects that care receivers exert on their mental wellbeing elude most studies. Therefore, the theoretical framework of the Actor-Partner Effect Interdependence Model (APIM), which discusses not only the objective partner effect but the subjective actor effect in the care-giving dyad, is suitable for this study. Secondly, while previous research has identified to some extent the influence of the different roles of the informal care-giver on the mental health of the care recipient, the focus remains on the intergenerational aspects, where the relationship between adult children and their parents is the major concern. However, as more types of care-givers, such as spouses, have become involved in informal care for older adults due to the decline of support 
from adult children, it is essential to expand the objects of research correspondingly, in order to establish a comprehensive picture of informal care-giving relationships. Besides, the majority of literature focusing on the interactive outcome within the carer-care receiver dyad adopted quantitative methods, which left the internal mechanism inexplicitly explained. Thus, introducing the mixed method consisting of the quantitative and qualitative method to articulate further the dynamic course and influential factors resulting in the association between care-giver and care recipient is crucial. Furthermore, the perspective of gender has eluded existing studies as an explanation of the association between care-giver type and the mental health of care recipients. While some research has explored the different mental health outcomes of care recipients based on the gender of their adult children, they interpreted it from the perspective of kinship rather than gender.

\section{Theoretical framework}

The major principle of the APIM is applied to construct the theoretical framework of this study. The original APIM was defined as a 'model of dyadic relationships that integrates a conceptual view of interdependence with the appropriate statistical techniques for measuring and testing it', which indicates that the model is applied to measure the interdependence within interpersonal relationships (Cook and Kenny, 2005). In the interdependent relationship, one party's emotions, cognition or behaviour affects the emotions, cognition or behaviour of their partner (Kelley et al., 2003). According to the model, the independent variable of an individual would influence his or her score on the dependent variable, which is known as the actor effect. There is also the partner effect, which indicates that the independent variable of an individual would impact the dependent variable of his or her partner (Fitzpatrick et al., 2016). Based on the model, 'actor effects' can be more universally defined as the effects of a person's own characteristics on his or her own outcomes, while 'partner effects' are defined as the effects of an individual's characteristics on a partner's outcome.

There are four patterns of actor-partner interdependence. The first, the 'couple' pattern, represents the situation in which the effect that a male has on his outcome is equivalent to the effect that the female has on his outcome, which can also be applied for the opposite scenario. In the second, the 'contrast' pattern, the direction of actor and partner effects are in opposition, with comparable absolute strength. The third, the 'actor-oriented' pattern, exists where the independent variable of male or female has a significant effect on his or her own outcome, while the partner effect has no statistical significance. In the final pattern, the 'partner-oriented' pattern which is quite rare, there is only a partner effect within the pairing, while the male and female have no significant influence on their own individual outcomes (Kenny et al., 2006; Kenny and Ledermann, 2010). The four patterns are explained based on samples in this study which are composed of heterosexual couples, but other gender partnerships exist which we did not take into account.

The Actor-Partner Effect has been widely explored in the care-giving dyad to uncover the interdependence of the care-giver and care recipient (Badr et al., 2017; Marguerite et al., 2017; Rippon et al., 2020). Considering that this study intends to uncover whether the gender and type of the care-giving dyad influences 


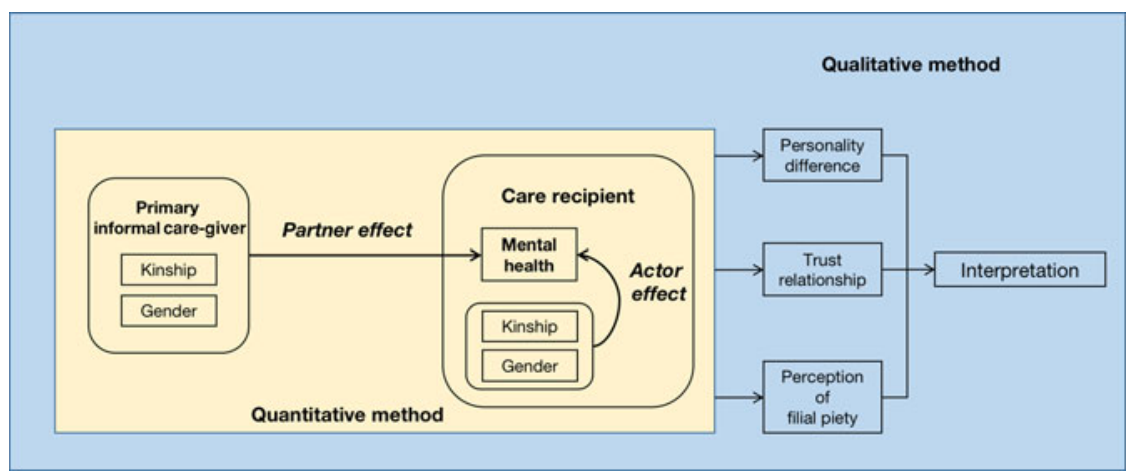

Figure 1. The theoretical framework.

the mental health of the care receiver, the Actor-Partner Effect is the best concept to clarify the influential path where both care-giver and care recipient play an influence. Compared with studies focusing on the lateral impact that the care-giver causes on the care recipient, the partner effect, this study aims to further identify whether the mental health of the care receiver is subject to the influence of their own characteristics, like gender and kinship, which is the actor effect in the APIM. Therefore, the crucial concepts in the APIM, the partner and actor effects, are the suitable theoretical tool to guide the research (Liu et al., 2017; Hoffman et al., 2019).

Based on the major concept of the APIM, this study initiates the idea to identify the relationship between the informal care-giving pair's role (in terms of gender and type), and the mental health of the care recipient, and uncover the essential dynamic course of the actor and partner effects using a mixed quantitative and qualitative method. To begin with, quantitative analysis will verify the existence of the proposed actor and partner effect. Then the qualitative method will be applied to interpret the mechanisms of the actor and partner effects from three angles (Figure 1).

\section{Data and methods}

\section{Data and measurements in the quantitative study}

This study used three waves $(2008,2011$ and 2014) of the CLHLS. The respondents to the waves before 2002 were the oldest old, but the number of elderly people aged 65 and above has been increasing in the waves since 2002, and in the later waves the data structure was more useful. These data are a follow-up survey conducted by the Centre for Healthy Ageing and Development Study of Peking University. The CLHLS was initiated in 1998 and approved by the Institutional Review Board at Duke University Medical Centre. Informed consent was obtained from each respondent. The CLHLS aimed to interview older adults aged 65 years and older, in a randomly selected sample from 22 provinces in China. The in-home interviews were carried out by a trained interviewer accompanied by a doctor, nurse or medical school student who performed a basic health examination for 
each participant. All respondents in the 2008 wave were re-interviewed in the 2011 and 2014 wave if they were still alive. If they died before the 2011 or 2014 wave, information was collected from their next of kin. To replace those who died before the 2011 wave, or those who were lost to follow-up due to refusal to participate or migration, the CLHLS recruited new participants of the same age and sex as the dropouts, to ensure that the sample remained comparable to previous waves.

The object of this study is older adults aged 65 and above who receive assistance with their ADLs. The older person's ADLs were measured by the internationally accepted Katz scale to determine whether they were disabled (Katz et al., 1963). The Katz scale includes six indicators: bathing, dressing, going to the toilet, controlling bowel movements, indoor walking and eating. If an older adult requires help to perform any of these six activities, the respondent is coded as disabled elderly.

For the robustness of the results, three waves of the data were pooled together to identify the relationship between the informal care-giving pair's role (in terms of gender and type) and the mental health of the care recipient. The 2008 wave included 1,975 respondents aged 65 years and older with a disability in performing at least one of six ADL items (bathing, dressing, toileting, indoor moving, incontinence and eating). The observations in 2011 and 2014 were 1,185 and 943, respectively. Because survivors were re-interviewed in the subsequent waves, strictly speaking we have 4,103 observations in total from 3,699 individuals. A variable indicating the interview wave was include in the analysis to control the time-series effect of different waves.

\section{Measures}

The gender and type of primary informal care-giver are two major categories in this study to represent the role of care-givers and to verify the existence of the partner effect. The type of informal care-giver is identified based on the question: 'Who is the primary care-giver when you need assistance with bathing, dressing, going to the toilet, transferring indoors, continence or eating?' The response categories were: spouse, son, daughter, daughter-in-law, son-in-law, grandchildren and their spouses, other relatives, friends/neighbours, social workers, housekeeper or nobody. Respondents were allowed to choose only one primary care-giver. The primary informal care-giver was recoded into four categories - spouse; son/daughter-in-law; daughter/son-in-law; and others - since son and daughter-in-law, or daughter and son-in-law always provided care-giving at the same time within the family context, and other people were simplified into one category due to the limited sample size. Considering that housekeepers accounted for 31.7 per cent of the total number of the variable 'others', they will represent the 'others' care-giver in the qualitative analysis. ${ }^{1}$ In the regression, the informal care-giver type is coded as a multi-category dummy variable with the daughter and son-in-law as the reference category.

The gender of the care-giver was identified as follows: if the gender of the care recipient was male and his or her spouse was the primary care-giver, then the gender of the care-giver was coded as female, and vice versa. Older spouses recruited in the CLHLS were all heterosexual partnerships, since the 'Marriage Law of the People's Republic of China' only recognises the monogamous marriage. The gender of the child care-giver was identified based on the kinship with the care recipient. 
It is noteworthy that informal care-givers coded as others were not included in the regression model due to the lack of information to identify their gender.

Considering the actor effect, the gender of the care recipient is included, where male is coded as 1 and female is coded as 0 . The care recipient's kinship is not coded as a new variable. Since the care recipient's type corresponds to the informal care-giver's type, including the care recipient's type would lead to the problem of collinearity in the regression. Therefore, the potential actor effect showing an impact of the care recipient's type on their own mental health can be tested by the partner effect based on the type of the informal care-giver. The mental health status of the care recipient is reflected by the seven questions in the questionnaire: 'Do you want to get things done?', 'Do you like to be clean and tidy?', 'Do you often feel nervous and afraid?', 'Do you often feel lonely?', 'Do you have the final say?', 'Do you think that the older you are, the less useful you are?' and 'Do you feel as happy as you were when you were young?' The answers to the first, second, fifth and seventh questions are conversely coded to get a positive ranking based on the logic of these questions. Code 1 in the answer represents 'very good', indicating the most positive outcome, therefore it is transformed into five points where the other answers are coded correspondingly $(2$ - 'good' $=4 ; 3$ - 'fair' $=3 ; 4$ - 'bad' $=2 ; 5$ - 'very bad' $=1$ ). The case with one answer of 'unable to answer' will be excluded. After the reliability test (Cronbach's alpha coefficient was 0.6810 in 2008, 0.6824 in 2011 and 0.6702 in 2014), the scores of the seven problem items were summed to get a mental health score of the older people, ranging from 7 to 35 points. Thus, the higher the score, the better the mental health of the care recipient.

Some predictive variables enrolled in the regression model for control were as follows: firstly, financial resources and education were included as indicators of SES, which have significant associations with health outcomes of elderly people (Strauss et al., 2010; Lei et al., 2014). Measures of SES included education (illiterate versus educated), financial independence (yes versus no) and better perceived economic status of their family compared to most neighbours (yes versus no). Besides, it was also necessary to take hukou (household registration), one of China's main socio-economic indicators, into account when assessing older adults' mental health (Guo et al., 2017).

Secondly, marital status and family support are supposed to have significant effects on mental health among elderly adults (Zhang and Li, 2011; Barnay and Juin, 2016). Accordingly, this article included marriage (whether currently married), number of living children and care-givers' willingness to provide care in the model.

Furthermore, with the ageing population trend living longer with clusters of illness, the prevalence of multimorbidity is increasing. There is growing evidence showing that multimorbidity contributes to the incidence of depression (Read et al., 2017). In this article, numbers of chronic diseases were controlled in the regression. In addition, given that multimorbidity might affect mental health through factors such as increasing symptom burden, disability and health-care utilisation (Katon, 2003), self-rated health and medical access were also taken into account in the analysis. 


\section{Statistical analysis}

Two models are constructed to clarify the association between the role of the primary informal care-giver and the care recipient's mental health using OLS regression. Considering that the dependent variable, the mental health score of the care recipient, is approximately normally distributed, the OLS regression model is the best choice to identify the possible association. The first model is used to verify the actor effect (that there is a gender difference in the subjective mental health of care recipients) and the partner effect (indicating there is a gender difference in the informal care-giver's impact on the mental health of the care recipient). In the second model, the relationship between the informal care-giver's type and the mental health of the care recipient is tested. All statistical analyses were performed using Stata version 15 (College Station, TX).

\section{Sample selection in the qualitative study}

In order to answer the question of why there are actor effects and partner effects between the type and gender of care recipients and informal care-givers, and the mental health of the care receivers, and to clarify further the internal dynamic course of these effects, this study chose community A and community B in Hangzhou, where older adults account for 13.6 per cent of the total resident population. Since researchers were collaborating with the local community health centre to survey the medical and caring needs of older adults in two communities, it offered a suitable chance for researchers to sift and recruit suitable interviewees. After the household survey, researchers would revisit the potential respondents and ask their willingness to be interviewed. Informed consent was obtained from each interviewee before data collecting. This study selected 12 samples of primary informal care-givers who met the following criteria, using a purposive sampling method that is the deliberate choice of a participant due to the qualities the participant possesses in terms of the researcher's needs (Bernard, 2002):

(1) The care-giver should have been providing support for the care recipient for no less than three months.

(2) The care-giver is undertaking the major care-giving responsibility compared with other family care-givers.

(3) For a care-giver who is the spouse, there should be at least one adult child available as a potential care-giver.

(4) For an adult child care-giver with siblings, the spouse of the care recipient should have passed away, and there should be at least one other care-giver available.

(5) If an only child is the primary care-giver, there should be no less than one other family member available.

Three housekeepers were included in the sample, since the housekeeper is the majority in the sub-group 'others' for informal care-givers (Table 1). Housekeepers in the qualitative analysis are middle-aged female migrant workers from rural areas whose reason for working as housekeepers in the urban city is to improve their income. Their responsibility is taking care of older adults with disabilities, and they live with older adults to cater to their emergent needs. Apart from 
Table 1. Characteristics of interviewees

\begin{tabular}{ccccccc}
\hline ID & Name & Gender & Age & Type & Care-giving span & $\begin{array}{c}\text { Condition of } \\
\text { care recipient }\end{array}$ \\
\hline 1 & Z & Female & 67 & Spouse & 19 years & Severe physical disability \\
\hline 2 & YW & Female & 53 & Housekeeper & 5 years & Mild cognitive decline; fracture \\
\hline 3 & Y & Female & 76 & Housekeeper & 10 years & Severe physical disability \\
\hline 4 & J & Male & 87 & Spouse & 26 years & Severe cognitive disability \\
\hline 5 & H & Female & 76 & Spouse & 6 months & Parkinson's disease \\
\hline 6 & Y & Female & 59 & Housekeeper & 3 months & Mild physical disability \\
\hline 7 & D & Male & 78 & Spouse & 2 years & Medium physical disability \\
\hline 8 & S & Female & 67 & Daughter & 8 months & Severe physical disability \\
\hline 9 & Q & Female & 66 & Daughter & 20 years & Severe physical disability \\
\hline 10 & M & Male & 50 & Son & 6 years & Medium physical disability \\
\hline 11 & DB & Male & 70 & Son & 10 years & Mild physical disability \\
\hline 12 & W & Female & 42 & Daughter & 3 months & Severe physical disability \\
\hline
\end{tabular}

assisting with the ADLs of care recipients, housekeepers are required to undertake housework, such as cleaning, cooking and running errands, as well as manage medical issues of care receivers, e.g. fetching prescribed medicine from the local community health centre and carrying out basic medical care.

In-depth interviews were conducted with these individuals, and the collected qualitative data were organised with a thematic analysis. In-depth interview is an effective way to get individuals to talk about their feelings, opinions and experiences from which insight can be gained into how they interpret and construct the world (Milena et al., 2008). In this study, the outline of the interview was devised in advance, which was revised several times during the practical interviews. During each interview, questions about the subjective experiences and feelings of interviewees were proposed depending on the actual situation to gather comprehensive data. Framework analysis, as a robust and methodical data analysis process, allows researchers to analyse raw qualitative data systematically and weave it into concepts which explain and improve the understanding of social behaviour. There are four categories of research questions that framework analysis can helpfully address: contextual, diagnostic, evaluative and strategic. In this study, the framework analysis is utilised to deal with the diagnostic question, disclosing the internal mechanism of the proposed actor and partner effects. While carrying out framework analysis, five stages are involved: familiarisation, identifying a framework, indexing, charting, and mapping and interpretation (Ritchie and Spencer, 1994; Furber, 2010).

\section{Results}

\section{Sample characteristics}

Table 2 demonstrates the characteristics of the study sample. The majority of older adults with disabilities (52.5\%) received informal care from their sons and 
Table 2. Characteristics of samples

\begin{tabular}{lll}
\hline Variable & $\%$ & SD \\
\hline Characteristics of care-giver: & & \\
\hline Daughter/son-in-law (yes =1) & 16.0 & 0.367 \\
\hline Spouse (yes =1) & 12.7 & 0.333 \\
\hline Son/daughter-in-law (yes =1) & 52.5 & 0.499 \\
\hline Others (yes =1) & 18.8 & 0.391 \\
\hline Willingness (yes =1) & 90.2 & 0.298 \\
\hline Care-giver gender (male =1) & 43.2 & 0.495 \\
\hline Characteristics of recipients: & & \\
\hline Mean mental health score & 24.29 & 4.248 \\
\hline Mean age & 92.79 & 9.257 \\
\hline Gender (male =1) & 37.6 & 0.485 \\
\hline Urban or rural residency (urban =1) & 29.3 & 0.455 \\
\hline Education (educated =1) & 42.0 & 0.494 \\
\hline Financial independence (yes = 1) & 78.9 & 0.408 \\
\hline Family is rich compared to neighbours (yes = 1) & 16.5 & 0.371 \\
\hline Currently married (yes = 1) & 19.6 & 0.397 \\
\hline Mean number of living children & 4.028 \\
\hline Medication (yes = 1) & 63.6 & 2.184 \\
\hline Good self-rated health (yes = 1) & 37.3 & 0.322 \\
\hline Number of non-communicable diseases & 6.238 \\
\hline Cognitive impairment (yes = 1) & 34.2 & 0.474 \\
\hline Wave 1 & 48.1 & 0.500 \\
\hline Wave 2 & 28.9 \\
\hline Wave 3 & 23.0 & 0.453 \\
\hline
\end{tabular}

Notes: $\mathrm{N}=4,103$. SD: standard deviation.

daughters-in-law, and adult children still played an important role in informal caregiving activities. The percentage of those who were currently married was low, which was close to the percentage of elderly adults who were taken care of by their spouses. It is noteworthy that most respondents were female, which is consistent with the consensus that the longevity of females is longer than for males. In terms of urban or rural residency, over 70 per cent of respondents came from rural areas. The average number of living children of the older adults with disability was around four, indicating that most care recipients had several potential informal care-givers. Considering health status, the majority of respondents reported poor self-rated health with six non-communicable diseases on average. What is more, about one-third of older adults with disability showed cognitive decline. 


\section{Research findings from the regression}

Table 3 presents the standardised correlation coefficients of care recipients' mental health with the gender and type of informal care-giver and care recipient. The first model explores the association between a care recipient's mental health and their own gender (the actor effect), and the association between the care recipient's mental health and their care-giver's gender (interpreted as the partner effect). Considering the gender of older adults with disability, male care recipients showed 0.57 units of better mental health than their female counterparts, which indicates the existence of the actor effect. On the other hand, disabled care recipients receiving informal care-giving from female care-givers were more likely to be in better mental health than their peers whose primary informal care-givers were male (the male care-giver would significantly decrease the care recipients' mental health by 0.44 units), which corroborates the partner effect in the care-giving dyad.

The second model verifies the relationship between a care recipient's mental health and their informal care-giver's type. As explained above, the potential actor effect showing the impact of a care recipient's type on his or her own mental health can be tested by the partner effect, based on the type of the informal caregiver. According to the regression result, older adults with disabilities who were cared for by a daughter (and son-in-law) showed significantly better mental health status than their counterparts whose primary informal care-giver was a son (and daughter-in-law). The care-giving provided by the son and daughter-in-law was associated with a decline in mental health of 0.63 units for their older parent in need. Furthermore, care recipients were more likely to have better mental health when a daughter (and son-in-law) was the primary informal care-giver than their peers who received informal care from other care-givers, such as a housekeeper. In the model, the 'other' kinds of care-givers were associated with reducing care recipients' mental health by 0.38 units compared with care provision by a daughter (and son-in-low).

The confounding variables indicate almost the same direction of association with mental health outcome in each model. Age demonstrated slightly positive association with mental health, which increased 0.012 units with one year of age growth (see Table 3, Model 2). Consistent with a previous study (Xu et al., 2016), there were socio-economic inequalities in mental health among older adults in China. Specifically, the urban residents had better mental health than the rural elderly. Besides, better financial background demonstrated a positive effect on mental health, and the educated showed slightly better mental health than the illiterate.

Furthermore, the currently married respondents showed slightly better mental health than the others (see Table 3, Model 1). Family support was primarily a successful explanatory variable for the mental health of the care recipient. Both caregiver's willingness and the number of living children had a positive effect on the care recipients' mental health. If the primary care-giver was willing to provide care, the care recipient's mental health would increase 1.641 units (see Table 3, Model 2); and mental health significantly increased 0.072 units with one more child (see Table 3, Model 2).

Simultaneously, better self-rated health was associated with better mental health, and the number of chronic diseases had a negative effect on mental health. Besides, 
Table 3. The result of ordinary least squares regression for the mental health of the care recipients[Q16]

\begin{tabular}{|c|c|c|}
\hline Variables & Model 1 & Model 2 \\
\hline Care-giver gender & $-0.435^{\star \star \star}$ & - \\
\hline (Female) & $(0.131)$ & - \\
\hline Spouse care-giver & - & -0.413 \\
\hline (Daughter/son-in-law) & - & $(0.305)$ \\
\hline Son/daughter-in-law care-giver & - & $-0.681^{\star \star \star}$ \\
\hline (Daughter/son-in-law) & - & $(0.175)$ \\
\hline Other care-giver & - & $-0.384^{\star}$ \\
\hline (Daughter/son-in-law) & & $(0.202)$ \\
\hline Recipient's gender & $0.632^{\star \star \star}$ & $0.512^{\star \star \star}$ \\
\hline (Female) & $(0.156)$ & $(0.140)$ \\
\hline Willingness & $1.328^{\star \star \star}$ & $1.641^{\star \star \star}$ \\
\hline (No) & $(0.238)$ & $(0.210)$ \\
\hline \multirow[t]{2}{*}{ Age } & 0.012 & $0.012^{*}$ \\
\hline & $(0.008)$ & $(0.007)$ \\
\hline Urban & $1.448^{\star * \star}$ & $1.304^{\star \star \star}$ \\
\hline (Rural) & $(0.153)$ & $(0.138)$ \\
\hline Education & 0.249 & $0.266^{\star}$ \\
\hline (No) & $(0.162)$ & $(0.146)$ \\
\hline Financial independence & $1.195^{\star \star \star}$ & $1.229^{\star \star \star}$ \\
\hline (No) & $(0.167)$ & $(0.154)$ \\
\hline Family is rich compared to neighbours & $1.132^{\star * \star}$ & $1.045^{\star \star \star}$ \\
\hline (no) & $(0.172)$ & $(0.157)$ \\
\hline Currently married & $0.322^{*}$ & 0.299 \\
\hline (No) & $(0.189)$ & $(0.238)$ \\
\hline \multirow[t]{2}{*}{ Number of children } & $0.064^{\star \star}$ & $0.072^{\star \star \star}$ \\
\hline & $(0.032)$ & $(0.028)$ \\
\hline Timely medication & $0.414^{\star \star \star}$ & $0.388^{\star \star \star}$ \\
\hline (No) & $(0.157)$ & $(0.143)$ \\
\hline Good self-rated health & $2.892^{\star \star \star}$ & $2.772^{\star \star \star}$ \\
\hline (No) & $(0.136)$ & $(0.124)$ \\
\hline \multirow[t]{2}{*}{ Number of non-communicable diseases } & $-0.027^{\star \star}$ & $-0.029^{\star \star \star}$ \\
\hline & $(0.011)$ & $(0.009)$ \\
\hline Wave 2 & $1.552^{\star \star \star}$ & $1.399^{\star \star \star}$ \\
\hline (Wave 1) & $(0.152)$ & $(0.138)$ \\
\hline
\end{tabular}


Table 3. (Continued.)

\begin{tabular}{lcc}
\hline Variables & Model 1 & Model 2 \\
\hline Wave 3 & $1.577^{\star \star \star}$ & $1.582^{\star \star \star}$ \\
\hline (Wave 1) & $(0.203)$ & $(0.184)$ \\
\hline Constant & $17.955^{\star \star \star}$ & $18.094^{\star \star \star}$ \\
\hline Observations & $(0.864)$ & $(0.788)$ \\
\hline$R^{2}$ & 3,331 & 4,103 \\
\hline
\end{tabular}

Note: (1) Category in the parentheses of a categorical or dummy variable is the reference category. (2) Numbers in parentheses show robust standard errors clustered at the person level.

Significance levels: Significant at ${ }^{\star} 10 \%,{ }^{\star *} 5 \%,{ }^{\star \star \star} 1 \%$.

the effect of timely medication was significantly positive. Ultimately, the mental health of the respondents improved over time, possibly due to the improved living conditions, sanitation, infrastructure and access to health services. The quantitative analysis suggests the existence of an Actor-Partner Effect between the informal care-giver and the care recipient, which indicates that the type and gender of both care recipient and care-giver influence the care receiver's mental health. However, quantitative analysis can only disclose the potential association between the variables. The fundamental dynamic course of these suggested effects remains vague. Therefore, it is essential to introduce the subjective experience of care recipients and care-givers, to understand fully the Actor-Partner Effects within caregiving dyads and the mechanism through which they have an influence.

\section{The socially constructed gender differences in role and Actor-Partner Effect}

Behind the Actor-Partner Effect (considering the gender of the care-giving dyad which is corroborated by the quantitative analysis), the internal influence mechanism fundamentally reflects the impact of the gender differences in socialisation.

During the process of socialisation, females and males follow the diverse requirement of their gender roles, where men are fostered to be strong and extroverted, and women to be sentimental and introverted. Such differences in personality affect their susceptibility to depression, which leads to a higher prevalence of depression among women than men (Goodwin and Gotlib, 2004). Growing up in the social context where traditional gender norms predominated, the marks of gender stereotype were apparent on the older adults with disabilities.

Faced with their decline in physical functioning, male older adults tended to be optimistic and strived to live independently, which was internalised into their personalities. They regarded their physical disability as a kind of 'difficulty' which must be conquered by their 'toughness'. HS, who has been living with Parkinson's disease for two years, insisted on doing most things by himself. Talking about his inconvenience in daily living, he proudly shared his childhood experience of breaking one of his arms. He said:

I didn't cry at that time, because my father always told me that a man must be tough and mustn't cry. And it is just a little injury for the tough man, in his 
words. He asked me to wash my face and rinse my mouth independently with one arm. So, this [disability] is nothing to me. You see, I can do everything by myself. (Interviewee 5, 12 August 2019)

By performing the activities of which they were capable, the male older adults with disabilities acquired feelings of being able to control their own body and overcome their physical limitations, which satisfied their inner masculinity. This spiritual power was significant for their mental health. As $\mathrm{H}$, the spouse care-giver of HS, said:

He doesn't like others to help him. He would get annoyed if others intervene in his business. He likes to do things by himself. (Interviewee 5, 12 August 2019)

Therefore, $\mathrm{H}$ would just stand by HS and watch him do various things on most occasions. Considering the requirements of the traditional gender role, it was taken for granted that men would undertake most responsibility; therefore, they were used to the feelings of mastery and competency. When physical disability became the barrier, men proactively tried to regain mastery of their life by doing things independently. The positive feedback they receive by successfully performing daily activities promotes their positive emotions.

It was different for their female counterparts. Female older adults were more likely to be negatively influenced by their physical limitations due to their stereotyped sentimentality and reliance. Faced with various difficulties with ADLs, female care recipients were haunted by thoughts of incapability. They tended to surrender to the hardships of performing ADLs independently, and relied on the help of informal care-givers. Such passive thoughts not only worsened the decline of their physical functioning, but further exacerbated their psychological burden towards disability, which negatively impacted their mental health. S, a daughter providing informal care for her disabled mother who had been in bed for eight months, expressed remorse about her mother's disability:

My mother required our help after she broke one of her legs a year ago, but she can also walk with the support of something. However, she kept saying that it was too painful to walk and she was reluctant to get off the bed. We gave in to her wish finally due to sympathy. It is this decision that led to her total independence because of the muscular atrophy ... I often saw her sigh and stare at the ceiling grimly. (Interviewee 8, 20 August 2019)

Immersed in negative thoughts of disability, the introversion of female care recipients hampered them from expressing their feelings with care-givers, which then accumulated inside. The build-up of grim thoughts not only directly influenced their mental wellbeing, but indirectly impacted it through spoiling the care-giving relationship, since their bad emotions eventually sought a vent. As S said:

My mum often suddenly lost her temper and slugged me, and I would fight back. Finally, she would accuse me of being an unfilial child. (Interviewee 8, 20 August 2019) 
Such things were repeated countless times, and after the bickering, the older lady would be more depressed. S confessed that she knew her mother did this out of misery caused by disability, but she just 'cannot' talk about her feelings frankly. They were accustomed to expressing their feelings in this way, which jeopardised the mental health of the care recipient.

In terms of the partner effect, the account of the mental health status differences due to the gender of the care-giver can also be viewed through the perspective of social gender roles. Women are traditionally regarded as suitable informal caregivers because they are more careful and meticulous, while men are negligent in doing chores like care-giving. This female care-giver pattern, especially in the context of China, is established and reinforced during the course of socialisation, where female children are exposed to traditional feminine activities such as doing household chores. Therefore, due to the process of socialisation, women are more likely to be adept at performing informal care-giving tasks. When $\mathrm{Z}$, a spouse care-giver who had been caring for her disabled husband for 19 years, was interviewed, she showed a paper to the interviewer which recorded the specific medicine that her care recipient should take every single day. She said:

You see, I would write down the medicine that he needs to take in advance, and marked it off after he eats it to make sure he follows the prescription ... he is unwilling to go to the nursing home, since he knows they cannot take care of him better than me ... I have been the most considerate compared with my brothers, because I began to do various housework when I was young. (Interviewee 1, 6 June 2019)

The ability to perform various household chores was cultivated and internalised by the female group. The high-quality care-giving provided by a skilled female caregiver could better satisfy the long-term care needs of the care recipient, which promoted their mental wellbeing.

In contrast to the high-quality informal care offered by female care-givers, male care providers tended to be careless in care-giving. The son care-giver $\mathrm{M}$ confessed that sometimes his mother would complain that the dishes he washed were still dirty, and the house was a mess even after he just finished the cleaning (Interviewee 10, 27 August 2019). From this indirect disclosure, it can be perceived that the dissatisfaction of the care recipient about their low-quality care-giving and unmet long-term care needs would negatively influence their mental wellbeing. Therefore, the Actor-Partner Effect concerning the gender of the care-giving dyad is fundamentally the result of different socially constructed gender roles.

It is noteworthy that the social division of gender roles in care-giving was reinforced by female care-givers themselves. While other male family members were available to provide informal care, the female care-givers were not likely to utilise these care-giving resources because of the deemed 'carelessness' of men. Female care-givers reckoned they were more qualified to carry out the care-giving tasks to satisfy the needs of the care recipients, and thus the male family members were excluded from informal care-giving by the females. W, a daughter care-giver engaged in informal care-giving for her father, which involved certain medical procedures, confessed that: 
My husband would give me a hand with care if I asked him to do so. But a man, as you can see, is not as careful as a woman, right? Therefore, I believe it is better to do those things all by myself. (Interviewee 12, 30 August 2019)

Care-givers S and Q also expressed that their husbands would only offer help occasionally with labour activities like turning over the care recipients. They themselves undertook the majority of care tasks, since they believed they were more 'reliable'.

\section{The significance of trust within the care-giving dyad}

As observed in the quantitative analysis, informal care-givers categorised as 'others' were associated with worse mental health for care recipients compared with having daughters (and sons-in-law) as the primary care-giver. This indicates the existence of an actor effect considering the relationship between care receiver and care-giver. The explanation of the actor effect utilises the housekeeper as a comparison.

The actor effect based on care recipient type can be analysed through the view of trust. While there is without question a solid trust relationship between a family care-giving dyad, it is not easy to establish trust between the older adults with disabilities and a stranger. Many care recipients cared for by a housekeeper experienced insecurity and suspicion due to their natural psychological defensiveness, which was exacerbated by bad news and gossip about housekeepers as care-givers for older adults. Besides this, conflicts caused by distrust between care recipients and housekeepers were another issue incurring negative emotions for care receivers. YW, a paid housekeeper who had been taking care of an older woman with cognitive impairment for five years, confessed the hardship of caring for her:

If she cannot find her key [which opens the drawer where she keeps valuables] or money, forgetting the place where she hides them, she would suspect me of stealing her things. And such a thing happens more and more frequently, since her memory is worse than two years ago ... She is quite suspicious, and several housekeepers left because of this ... And she doesn't allow you to watch television, or open the air conditioner during the summer. She would even unplug the air conditioner if you insist on opening it. (Interviewee 2, 3 July 2019)

Given this lack of trust, the conflicts between care recipients and housekeepers were frequent and hard to solve, and the ensuing negative emotions would deposit at the bottom of the heart of care recipients all the time. Subjected to these negative emotions, older adults with disabilities were more likely to experience worse mental health. However, the conflicts between family care-giving dyads is another story. As care-giver $\mathrm{W}$ said:

I would argue with my father, but after a while, we just restore good relations. There is no such thing as lasting conflict between family members, right? (Interviewee 12, 26 July 2019)

For this family care-giving dyad, conflicts were momentary, and the negative emotions dissipated naturally. The value of trust can be perceived from this. 
Several family care-givers said that they had proposed to hire a housekeeper to take care of their parents, but each of the older adults with disabilities rejected the idea without compromise. The older people reckoned that housekeepers 'cannot be trusted', and they were afraid of being badly cared for or even tortured by them, while being taken care of by their family members brought the feelings of 'security' and 'ease' which were emphasised by most care recipients. For elderly people who had grown up in China, where family played the predominant role in caring for older adults, they believed in their family members, while the commercial relationship with a housekeeper based on the market economy seemed more unreliable. Like YW said 'she would go to her son's home nearby accusing me of stealing' (Interviewee 2, 3 July 2019). But the older woman with dementia would not make such accusation of her child. Therefore, trust was the basis of harmonious care-giving relationships which influenced the mental health of care recipients. For the older adults with disabilities who were cared for by a housekeeper or another stranger, the lack of trust negatively impacted their mental wellbeing due to the accumulation of unresolved passive emotions, while the solid trust between family members provided the care recipient with security which was fundamental for their mental health.

\section{Son versus daughter: different perceptions towards filial piety}

While the partner effect due to gender differences has been explained above, the reason why there is a difference in the mental health outcomes of care recipients based on the type of adult child care-giver requires further analysis. Hu (2018) proposed a dual model for the filial piety of adult children, which indicates that authoritarian filial piety (emphasising authority relationships and children's duty) increases children's financial support for parents, while reciprocal filial piety (which stresses family love and equity) promotes children's emotional support in care-giving. This model offers a novel way to analyse the difference towards filial piety and related behaviours between the sons and daughters as primary care-givers.

Drawing from their narratives, sons were more likely to perceive care-giving as an indispensable duty of filial piety, while daughters tended to deem offering care to disabled parents to be a reciprocal process. It is noteworthy that sons emphasised 'responsibility' more when talking about their motivations for undertaking caregiving tasks as the primary care-giver. They reckoned that to take care of their parents when they were in need was inevitable as a basic requirement of traditional social norms; therefore, they 'have to' undertake the responsibility, apparently influenced by authoritarian filial piety. As one son, DB, said:

You can be reluctant to do this [care-giving] inside, but you have to do this. Or how will others judge you? (Interviewee 11, 28 August 2019)

The fear of social moral condemnation, which is a potential outcome for failure to perform duties, was another major force that pushed them to undertake the task of care-giving. In Chinese society, where filial piety has long been promoted, supervision from the society and acquaintances is the major force maintaining the elderly 
care model of sons' care-giving. Since the adult children care-givers of this generation grew up in this society of acquaintances, its traditional binding force on caregiving responsibility still functions.

Daughters tended to view care-giving duty from the perspective of reciprocity, which is apparent from their statements of the endeavours that their parents contributed for them. When $\mathrm{S}$ was asked why she insisted on taking care of her mother by herself, she instantly recalled her mother's dedicated work in raising and caring for her:

My mother raised me from an early age and it was very hard. When I was nine years old, my father was gone. She has been taking care of us and looking after us alone ... I am a cancer patient; my mother took care of me when I was sick 15 years ago ... so when they [siblings] proposed to send our mother to a care home, I refused and cried. I said, Mum's life had been so hard, and I couldn't bear it. If she was sent to a care home, you could count the remaining days of her life. I can imagine that she would be tortured if she woke up in the care home, and saw none of us. Like the nurse said, she is happy as long as she can see us. (Interviewee 8, 20 August 2019)

For daughters, caring for their parents with disability was more like a process to repay them rather than simply fulfilling their responsibilities. There was a stronger emotional connection between daughters and care recipients which propels them to take good care of their parents with disability.

It is the different perceptions towards filial piety of adult child care-givers that led to the discrepant results in the mental health of care recipients. Sons, who viewed the task of caring as an inevitable responsibility from the perspective of authoritarian filial piety, mainly focused on the accomplishment of their direct long-term care needs. When the direct care needs were satisfied, they would reckon that they had completed their duty. In the meantime, the mental health of care recipients eluded most care-giver sons' attention. $\mathrm{M}$, for instance, always left his mother watching television alone in her room, while he played with his smartphone in his room. The lack of communication and companionship undoubtedly increased the loneliness of care recipients, which negatively affected their mental health. On the other hand, daughters, perceiving the offering of care as a reciprocal process, paid more attention to the emotional needs of their older parents with disabilities, which promoted the mental health of the care recipients. As care-giver daughter W said, 'When I was little, my father raised me. Now it is time for me to take good care of him. I want him to be happy and satisfied' (Interviewee 12, 30 August 2019). For them, caring for their parents with disabilities not only needed to satisfy the long-term care needs of the care recipients, but also to ensure their spiritual wellbeing. Unlike the passive fulfilment of care-giving responsibilities, care-giver daughters who believed in reciprocal filial piety provided informal care more proactively. The daughter respondents unanimously mentioned their wishes to 'treat [their] parents well' and 'make them more comfortable and happier' (Interviewees 8 and 9, 20 August 2019). The force behind their care-giving behaviour was gratitude for their parents' dedicated work in bringing them up. 


\section{Discussion and conclusion}

\section{Reflection on the socially constructed gender differences}

While current research has explored the relationship between care-givers and the wellbeing of care recipients, such association has been interpreted from the perspective of the care-giver's role, discussing how carers with different roles influence the mental health outcome of the care receivers (Zeng et al., 2016; Hu and Chen, 2019). However, this study spots that it is gender that plays a major part in the differential mental health outcomes of care recipients.

The study findings indicate that there is a gender difference in the partner effect on care recipients' mental health, due to the discrepant informal care quality depending on the gender of the care-giver. This discrepancy should be ascribed to the division of social gender roles which moulds women into qualified caregivers through socialisation (Hooyman, 1992; Stoller, 1993). It is noteworthy that female care-givers not only follow the division of gender roles in care-giving, but reinforce the division themselves. This finding provides a clue to the developing daughter preference in informal elderly care. While the elevated SES of women and power equity within the core family partly liberates women from the responsibility of caring for their husband's parents, they are again heavily involved in the task of caring for their own parents (Chi and Merril, 2011). However, the efforts that women put in do not result in equivalent gains. The literature demonstrates that daughters provide more but receive less, which means that although daughters provide more money and housework to their parents than sons do, their chances of receiving either downstream or upstream transfers from their parents are still comparatively low $(\mathrm{Hu}, 2017)$. Such an asymmetrical pattern across genders requires reflection on the socially constructed division of gender roles in care for older adults. While the so-called daughter preference develops in care for older adults, it only results in more responsibility for women. Therefore, as part of the change in patterns of informal care-giving preference, equity and the lasting division of social gender roles between care-giving sons and daughters requires corresponding reconstruction.

In addition, this research discloses that male care recipients benefiting from the traditional gender role requirements enjoy better mental health outcomes compared with female care recipients. Confronted with disabilities, female care recipients are more likely to immerse themselves in negative thoughts and less likely to challenge their adversities. While current research has not explored this phenomenon, it is necessary to take a step further in understanding the gendered nature of responses to chronic conditions and corresponding outcomes; and these findings indicate that older women with disabilities, who are vulnerable to both physical and mental disorders, should receive more attention in long-term care (Zhuang and Zhang, 2016).

\section{Constructing a care-giver-care receiver trust relationship within a non-relatives care-giving dyad}

How to establish a trust relationship between the older care recipient and an employed care-giver is a significant challenge exacerbating with the population ageing. While the responsibility for care-giving is still mainly taken by family, more 
and more housekeepers are being introduced into informal care-giving to compensate for the insufficiency of family care resources resulting from the socio-economic change and prevalence of the '4-2-1' family structure (Chen et al., 2018). Unlike developed countries hiring individuals from the developing world to provide home care services for frail older adults, female migrant workers from rural areas are the major choice for Chinese urban households faced with elder-care tasks (Ayalon, 2009). Since growing numbers of female migrant workers are moving into cities for higher income, being a housekeeper caring for older adults, which barely requires a high education background, becomes a good choice for them. Also families in need prefer women care-givers who are reckoned to be more skilled at care-giving. However, the lack of trust between the older care-receiver and the housekeeper leads to negative consequences for the mental health of older adults according to this study. In addition, the distrust among older people towards housekeepers is further provoked by news of elder abuse on social media. On 2 May 2020, an older woman with disabilities, abused by former two housekeepers, was smothered by the new housekeeper who had committed several similar crimes, and this sparked heated public concern (Zhang, 2020). The spreading of such news undoubtedly arouses the sense of insecurity in older people with disabilities who are taken care of or will be cared by housekeepers, which would negatively impact their mental wellbeing. Besides, the differences in personality and lifestyle between the older adults with disabilities and the housekeepers, compounded with heavy eldercare burden, increase the likelihood of conflicts within care-giving dyads. Therefore, there is an urgent need to improve the informal care-giving quality provided by housekeepers and to develop a supervision system to protect the rights of the care recipients, based on which the trust relationship between older care receivers and housekeepers can be established.

Introducing a mixed method, this study explores the potential Actor-Partner Effect of gender and type of both older adult with disability and care-giver, on the mental health of care recipients. Based on the OLS regression result, which indicates the existence of the proposed Actor-Partner Effect, a qualitative method was used to explain and complement the dynamic course of the Actor-Partner Effect within the care-giving dyad. From the perspective of gender, this study clarified that the Actor-Partner Effect should be attributed to social constructions. Reflecting the socially constructed gender difference in informal care-giving, we propose to reconstruct a more equal informal care-giving pattern. While female care receivers' mental wellbeing is subject to more negative impact deriving from disability and the socialisation process with gender division, they should receive more attention and support. As growing numbers of elderly people with disabilities are taken care of by housekeepers, establishing a trust relationship within the nonrelative care-giving dyad becomes an urgent problem which is associated with the mental health of older care recipients.

Also there are certain problems that we intend to resolve in future research. In this study, we utilise the principal concept of APIM which is designed to identify the interdependence within the care-giving dyad, however the existence of the Actor-Partner Effect on the care-giver's side has been examined. Since questions concerning the mental health of the care-giver were not incorporated into the CLHLS questionnaire, we are unable to clarify whether the mental wellbeing of 
the care-giver is influenced by their own and the care recipient's role through quantitative study. While existing research has proposed that there is role differential in care-giver's subjective burden, we plan to determine further the Actor-Partner Effect, based on the perspective of gender and type of care-giving dyad, on the caregiver's mental health and internal mechanism (Gallicchio et al., 2010).

Author contributions. All four authors contributed to this paper.

Financial support. This work was supported by a Project of Humanity and Social Science Youth Foundation of Ministry of Education (20YJC840019); a Project of the National Nature Science Foundation of China (grant number 72004201); and a Major Project of National Social Science Foundation of China (grant number 13\&ZD163).

Ethical standards. This is a semi-structural interview, so no ethical approval was required for this study.

Conflict of interest. The authors declare no conflicts of interest. The contents of this publication are solely the responsibility of the authors.

\section{Note}

1 The sample of housekeepers was 394 , which is too small to reach statistical significance in the OLS regression model, therefore, it was not coded as an independent variable.

\section{References}

Allen SM and Mor V (1997) The prevalence and consequences of unmet need: contrasts between older and younger adults with disability. Medical Care 35, 1132-1148.

Ayalon L (2009) Fears come true: the experiences of older care recipients and their family members of live-in foreign home care workers. International Psychogeriatrics 21, 779-786.

Badr H, Federman AD, Wolf M, Revenson TA and Wisnivesky JP (2017) Depression in individuals with chronic obstructive pulmonary disease and their informal caregivers. Aging \& Mental Health 21, 975-982.

Barnay T and Juin S (2016) Does home care for dependent elderly people improve their mental health. Journal of Health Economics 45, 149-160.

Bernard HR (2002) Research Methods in Anthropology: Qualitative and Quantitative Approaches, 3rd Edn. Walnut Creek, CA: Alta Mira Press.

Buber I and Engelhardt H (2008) Children's impact on the mental health of their older mothers and fathers: findings from the Survey of Health, Ageing and Retirement in Europe. European Journal of Ageing 5, 31-45.

Byers AL, Levy BR, Allore HG, Bruce ML and Kasl SV (2008) When parents matter to their adult children: filial reliance associated with parents' depressive symptoms. Journals of Gerontology: Psychological Sciences and Social Sciences 63B, 33-40.

Centers for Disease Control and Prevention (2019) Disability and Health Related Conditions. Available at https://www.cdc.gov/ncbddd/disabilityandhealth/relatedconditions.html.

Chen S, Zheng J, Chen C, Xing Y, Cui Y, Ding Y and Li X (2018) Unmet needs of activities of daily living among a community-based sample of disabled elderly people in eastern China: a cross-sectional study. BMC Geriatrics 18, 160.

Chi I and Merril S (2011) Intergenerational family support for Chinese older adults. International Journal of Social Welfare 20, S1-S3.

Cook WL and Kenny DA (2005) The actor-partner interdependence model: a model of bidirectional effects in developmental studies. International Journal of Behavioral Development 29, 101-109.

Deutsch FM (2006) Filial piety, patrilineality, and China's one-child policy. Journal of Family Issues 27, 366-389.

Ebenstein A and Leung S (2010) Son preference and access to social insurance: evidence from China's rural pension program. Population and Development Review 36, 47-70. 
Ejem D, Bauldry S, Bakitas M and Drentea P (2018) Caregiver burden, care recipient depressive symptomology, and social exchange: does race matter? Journal of Palliative Care 33, 100-108.

Fitzpatrick J, Gareau A, Lafontaine M and Gaudreau P (2016) How to use the Actor-Partner Interdependence Model (APIM) to estimate different dyadic patterns in MPLUS: a step-by-step tutorial. Quantitative Methods for Psychology 12, 1-13.

Furber C (2010) Framework analysis: a method for analysing qualitative data. African Journal of Midwifery and Women's Health 4, 97-100.

Gallicchio L, Siddiqi N, Langenberg P and Baumgarten M (2010) Gender differences in burden and depression among informal caregivers of demented elders in the community. International Journal of Geriatric Psychiatry 17, 154-163.

Goodwin RD and Gotlib IH (2004) Gender differences in depression: the role of personality factors. Psychiatry Research 126, 135-142.

Guo J, Guan L, Fang L, Liu C, Fu M, He H and Wang X (2017) Depression among Chinese older adults: a perspective from Hukou and health inequities. Journal of Affective Disorders 223, 115-120.

Hannum E (2005) Market transition: educational disparities, and family strategies in rural China: new evidence on gender stratification and development. Demography 42, 275-299.

Hoffman GJ, Sarah B, Mendez-Luck CA and Gaugler JE (2019) Interdependence in health and functioning among older spousal caregivers and care recipients. Western Journal of Nursing Research 41, 685-703.

Hooyman NR (1992) Social policy and gender inequities in caregiving. In Dwyer JW and Coward RT (eds), Gender, Families, and Elder Care. Newbury Park, CA: Sage, pp. 181-201.

Hu A (2017) Providing more but receiving less: daughters in intergenerational exchange in mainland China. Journal of Marriage and Family 79, 739-757.

Hu A (2018) The diversification of children's support for their parents in the context of an aging society: concepts and behavior. Social Sciences in China 39, 114-136. (In Chinese)

Hu A and Chen F (2019) Which child is parents' preferred caregiver/listener in China? Research on Aging 41, 390-414.

Katon W (2003) Clinical and health services relationships between major depression, depressive symptoms, and general medical illness. Biological Psychiatry 54, 216-226.

Katz S, Ford AB, Moskowitz RW, Jackson BA and Jaffe MW (1963) Studies of illness in the aged: the index of ADL: a standardized measure of biological and psychosocial function. Journal of the American Medical Association 185, 914-919.

Kelley HH, Holmes JG, Kerr NL, Reis HT, Rusbult CE and Van Lange PAM (2003) An Atlas of Interpersonal Situations. New York, NY: Cambridge University Press.

Kenny DA and Ledermann T (2010) Detecting, measuring, and testing dyadic patterns in the actor-partner interdependence model. Journal of Family Psychology 24, 359-366.

Kenny DA, Kashy DA and Cook WL (2006) Dyadic Data Analysis. New York, NY: The Guilford Press.

Lei X, Sun X, Strauss J, Zhang P and Zhao Y (2014) Depressive symptoms and SES among the mid-aged and elderly in China: evidence from the China Health and Retirement Longitudinal Study national baseline. Social Science \& Medicine 120, 224-232.

Li M and Dai H (2019) Determining the primary caregiver for disabled older adults in mainland China: spouse priority and living arrangements: caregiver selection for disabled older adults. Journal of Family Therapy 41, 126-141.

Liu S, Li C, Shi Z, Wang X, Zhou Y, Liu S, Liu J, Yu T and Ji Y (2017) Caregiver burden and prevalence of depression, anxiety and sleep disturbances in Alzheimer's disease caregivers in China. Journal of Clinical Nursing 26, 1291-1300.

Luo BZ and Zhan SH (2018) Crossing the river by feeling for the stones: contesting models of marketization and the development of China's long-term care services. Journal of Chinese Governance 3, 438-460.

Lyons KS, Zarit SH, Sayer AG and Whitlatch CJ (2002) Caregiving as a dyadic process. Journals of Gerontology: Psychological Sciences and Social Sciences 57B, P195-P204.

Marguerite S, Laurent B, Marine A, Tanguy L, Karine B and Pascal A (2017) Actor-partner interdependence analysis in depressed patient-caregiver dyads: influence of emotional intelligence and coping strategies on anxiety and depression. Psychiatry Research 258, 396-401.

Marks NF and Choi LH (2002) Transitions to caregiving, gender, and psychological well-being: a prospective U.S. national study. Journal of Marriage and Family 64, 657-667. 
Milena ZR, Dainora G and Alin S (2008) Qualitative research methods: a comparison between focus-group and in-depth interview. Annals of the University of Oradea, Economic Science Series 17, 1279-1283.

Mu G (2016) Silver Hair China: From Comprehensive Two Children to Successful Aging. Beijing: China Democracy and Legal Publishing House. (In Chinese)

Newsom JT and Schulz R (1998) Caregiving from the recipient's perspective: negative reactions to being helped. Health Psychology 17, 172-181.

Pinquart M and Sorensen S (2011) Spouses, adult children, and children-in-law as caregivers of older adults: a meta-analytic comparison. Psychology and Aging 26, 1-14.

Purdy J and Arguello D (1992) Hispanic familism in caretaking of older adults: is it functional? Journal of Gerontological Social Work 19, 29-43.

Read JR, Sharpe L, Modini M and Dear BF (2017) Multimorbidity and depression: a systematic review and meta-analysis. Journal of Affective Disorders 221, 36-46.

Rippon I, Quinn C, Martyr A, Morris R, Nelis SM, Jones IR, Victor CR and Clare L (2020) The impact of relationship quality on life satisfaction and well-being in dementia caregiving dyads: findings from the IDEAL study. Aging \& Mental Health 24, 1411-1420.

Ritchie J and Spencer L (1994) Qualitative data analysis for applied policy research. In Bryman A and Burgess RG (eds), Analyzing Qualitative Data. London: Taylor and Francis, pp. 173-194.

Rozzini R, Frisoni GB, Sabatini T and Trabucchi M (2002) The association of depression and mortality in elderly persons. Journals of Gerontology: Biological Sciences and Medical Sciences 57A, M144-M145.

Sheng X and Settles BH (2006) Intergenerational relationships and elderly care in China: a global perspective. Current Sociology 54, 293-313.

Stoller E (1993) Gender and the organization of lay health care: a socialist-feminist perspective. Journal of Aging Studies 7, 151-170.

Strauss J, Lei X, Park A, Shen Y, Smith, JP, Yang Z and Zhao Y (2010) Health outcomes and socioeconomic status among the elderly in China: evidence from the CHARLS pilot. Journal of Population Ageing 3, 111-142.

Tang C, Ma J and Shi J (2009) Ethics and fairness of daughter's supporting of her parents' family: gender study on intergenerational family relations in a rural area of eastern Zhejiang Province. Sociological Research 6, 18-36. (In Chinese)

The National Working Commission on Aging (2016) Three Departments Released the Results of the Fourth Sample Survey on the Living Conditions of Urban and Rural Elderly in China. Available at http://www.cncaprc.gov.cn/contents/2/177118.html.

Williamson GM, Martin-Cook K, Weiner MF, Svetlik DA, Saine K and Hynan LS (2005) Caregiver resentment: explaining why care recipients exhibit problem behavior. Rehabilitation Psychology 50, 215-223.

Wolff JL and Agree EM (2004) Depression among recipients of informal care: the effects of reciprocity, respect, and adequacy of support. Journals of Gerontology: Psychological Sciences and Social Sciences 59B, 173-180.

World Health Organization (2017) Mental Health of Older Adults. Available at https://www.who.int/newsroom/fact-sheets/detail/mental-health-of-older-adults.

Xie Y and Zhu H (2009) Do sons or daughters give more money to parents in urban China? Journal of Marriage and Family 71, 174-186.

Xu Y, Yang J, Gao J, Zhou Z, Zhang T, Ren J, Li Y, Qian Y, Lai S and Chen G (2016) Decomposing socioeconomic inequalities in depressive symptoms among the elderly in China. BMC Public Health 16, 1-9.

Yan Y (2009) The Individualization of Chinese Society. Oxford: Berg.

Zeng Y, George L, Sereny M, Gu D and Vaupel JW (2015) Older parents enjoy better filial piety and care from daughters than sons in China. American Journal of Medical Research 1, 244-272.

Zeng Y, Brasher MS, Gu D and Vaupel JW (2016) Older parents benefit more in health outcome from daughters' than sons' emotional care in China. Journal of Aging and Health 28, 1426-1447.

Zhan HJ (2004) Willingness and expectations: intergenerational differences in attitudes toward filial responsibility in China. Marriage \& Family Review 36, 175-200. 
Zhang X (2020) Jiangsu a housekeeper smothered an 83-year-old woman, family members said she had wanted to leave because of salary problems. The Beijing News, May 12. Available at http://www. bjnews.com.cn/news/2020/05/12/726734.html.

Zhang B and Li J (2011) Gender and marital status differences in depressive symptoms among elderly adults: the roles of family support and friend support. Aging \& Mental Health 15, 844-854.

Zhang W and Wang Y (2010) Meal and residence rotation of elderly parents in contemporary rural northern China. Journal of Cross-cultural Gerontology 25, 217-237.

Zheng X, Liu L, Pang L, Qiu Y, Yang C, Chen Q, Zhou Y and Li Q (2012) Effects of rapid economic development on traditional patterns of elder support in China. Journal of Population Ageing 5, 163-176.

Zhuang X and Zhang L (2016) Analysis of the state of eldercare for older people with disabilities. Population Journal 3, 47-57. (In Chinese)

Cite this article: Huang S, Zhao Q, Liu X, Jin Y (2022). The role of care-giver and mental health for older adults with disabilities: a mixed-method study. Ageing \& Society 1-25. https://doi.org/10.1017/ S0144686X21001409 